\title{
Augmented Reality Technology for Vocational Education in the Disruption Era
}

\author{
Ulfah Mediaty Arief, Hari Wibawanto, Azzizah Luhur Nastiti \\ Engineering Faculty \\ Universitas Negeri Semarang \\ Semarang, Indonesia \\ luhurnastiti@students.unnes.ac.id
}

\begin{abstract}
The purpose of this paper is to explain information and communication technology that can support the field of education in the disruption era, namely Augmented Reality (AR). The contribution of $A R$ in education can provide a learning experience. Vocational education is an education that requires balance between acquiring knowledge and building experiences. In this way, $A R$ can be one of the technologies that support vocational education. We will explain the potential case of $A R$ game development in AR game development that is applied in education, especially in learning chemistry.
\end{abstract}

Keywords - augmented reality, vocational education

\section{INTRODUCTION}

Information and communication technology (ICT) has developed year by year. These developments have impact on various sectors such as transportation, health, banking, government and education. Education field began to emerge various new platforms such as MOOC (Massive Open Online Course), Mobile learning, and E-learning. The other sectors that also emerge are such as smart city technology and $\mathrm{O} 2 \mathrm{O}$ service (Online to Offline). This era is called disruption era, that is an era where innovation can replace old, unsophisticated, impractical, inefficient, and unproductive technology with digital technology that produces something new, more efficient, faster, cheaper, easier and more useful. In addition to disruption, there are innovations that have an impact on cutting the cost of production stages in the form of labor and affecting the creation of employment called efficiency innovation [1]. Digitalization and automation in various industries have an effect on preparing for a digital-based industry revolution. One of area in education field that needs to be improved is vocational education that prepares people to make technical rigorous procedures, that must be properly assimilated and enforced, many of which attached to technicalities, rules and safety standards [2].

Some ICT developments such as Virtual Reality, Augmented Reality and Internet of Things began to have a role in education. Virtual Reality (VR) is a simulation technology that allows users to interact with the environment that is in the virtual world. Augmented Reality (AR) is a technology that uses tools like smartphones or tablets in projecting virtual objects such as illustrating the proper use of techniques on an object or showing the shape of a model into a real environment. While Internet of Things (IoT) is a concept where objects that are often used in everyday life such as smartphones are connected to one network and data from that network can be utilized for other needs [3].

In the digital age, the needs of technology and workings are changing, especially in vocational education. Learning by conventional methods and work methods that typically use properties and instruments, AR offers its potential to visualize instruments in learning to gain a different learning experience.

Potential of AR has not been applied maximally and is still rarely used in vocational education especially in learning. The most notably reason is the creation of complex and constrained content and development on resources and costs [4].

In the industrial field, interconnected production processes can cause complexity so that employees are required to be able to follow the complexity. Education in the operation and maintenance of machinery is often important in the technical training process. The machines are getting more complex and increasing automation. AR is best suited to prepare employees during education with the potential to integrate both the real world and the digital world. Such an AR describes a combination of interactive and dynamic digital information and data with real and surrounding objects [5] [6].

Several studies have shown that AR can be used in designing exploratory learning activities with the Gamification approach [7]. Because AR is able to combine real-world and digital and can be used for learning like machine visualization. In this research, the writer applies Augmented Reality technology in education especially in learning chemistry, which explains about chemical bond. This case study can be an example to apply in vocational education.

\section{METHOD}

Research about how to improve the learning experience using technology increasingly focuses on the latest technologies such as AR, ubiquitous learning (u-learning), mobile learning (m-learning), and games [8]. One of the technologies that is the most potential one and requires development is AR [9]. The rapid technological evolution has had an impact in education field, especially when technology is combined with adequate pedagogical base. This combination has created new opportunities to improve the quality of the teaching and learning experience [10]. 
Media for learning is evolving and has a focus on facilitating, creating user effectiveness and user-friendliness in understanding a material [11]. In recent years, there has been considerable effort in the use of technology to support and enhance learning [12]. The integration of learning environments, among others, are the use of computers, multimedia materials, whiteboard, internet, simulations, games and more recently the use of smartphone devices and deep technology such as 3D virtual world and AR [13].

$\mathrm{AR}$ is a technology that can display virtual elements into the user environment [14]. Ideally, virtual elements should interact with users and objects in the real-world naturally. The main goal is to create a system so that the user cannot distinguish between the real world and the virtual augmentation [15].

\section{RESUlT AND DISCUSSION}

AR technology is effective for students to learn something not seen in the real world and abstract or complex concepts [16]. One of the topics that contains abstract concepts is chemistry [17]. Visualization using technology such as animation is one of the learning strategies that encourages visualization skills that can help to understand concepts correctly [18]. The medium used for the study of chemistry today is a chemical book with color images and lab work in lab. While not all problems can be understood by reading books and practices in the laboratory that can be done anywhere and anytime, suitable media are needed to improve the understanding of chemical concepts appropriately and effectively [19]. AR technology enhances the user's sensitivity through visualization of images, text, 3D models into real environments via camera, so that enabling the delivery of information to be more effective [20].

AR can be developed with the concept of the game. The development of AR has been found in the form of educational games and has the advantage of improving gameplay variations and potentially producing a unique educational ability [21]. AR games involve rules of play, teamwork and a sense of excitement to engage students in the learning experience [22]. The gaming industry is an attractive industry and has the largest consumer [23]. Making games using real-world content and virtual worlds can create memorable and interactive experiences [24]. This is then behind the emergence of media innovation in learning chemistry, especially the development of AR technology as a media of learning.

The media developed by researchers is the ARChemy game. The ARChemy game concept of each level game will be given quizzes about chemical bonds that include ionic bonds and covalent bonds. This ARChemy game has 10 levels. On the Main Menu page, there are three menu options, "Start", "How to Play", and "Profile". If the player selects the "How to Play" menu, then the system will display information on how to use the app. If the player chooses the "Profile" menu, then the system will display information about the game and the developer. If the player chooses the "Start" menu, the application will activate the camera automatically and will enter level 1 then the quiz question will appear on the bottom screen. The player must direct the camera towards the target form. When the camera captures the marker image, it will show 3D objects in the form of atomic and electron animation. Players should look for a combination of markers by placing markers aligned. If the atom objects attract each other, then the answer is correct. If successfully answered, then the player will be able to go to the next level and get rewards in the form of information about the ties related to the quiz question. If the marker combination is incorrect, a warning appears.

In the development of the ARChemy game, the researcher performs several stages of making the initial design of the product to be developed, making the assets needed in making the application using graphic software, developing applications with game engine that is Unity $3 \mathrm{D}$ and Vuforia SDK. There are six 3D objects: visualization of Hydrogen $(\mathrm{H})$, Sodium $(\mathrm{Na})$, Nitrogen $(\mathrm{N})$, Oxygen $(\mathrm{O})$, Fluor $(\mathrm{F})$, and Chlorine $(\mathrm{Cl})$ atoms, with electron animations orbiting atoms. On the smartphone screen, a problem is displayed and the camera will be activated to detect the marker and the system will display the customized object.

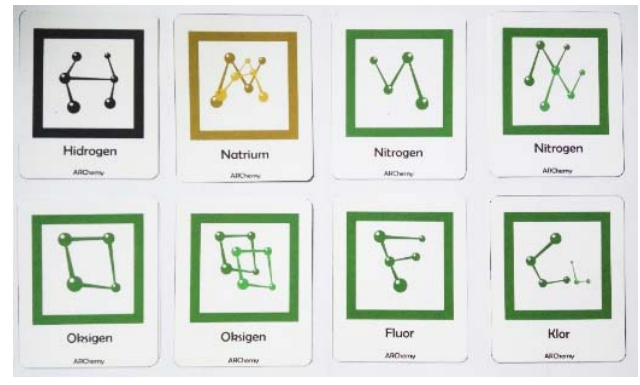

Fig. 1. ARChemy's Marker

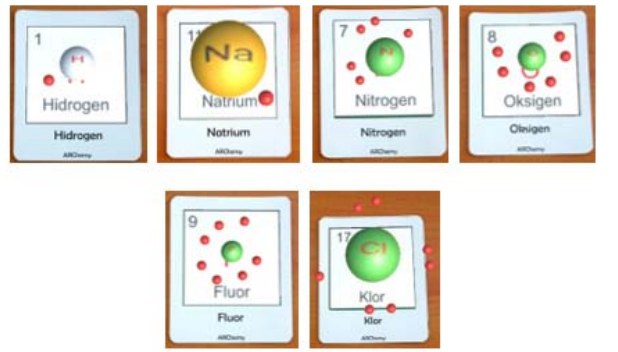

Fig. 2. 3D Objects and Animation

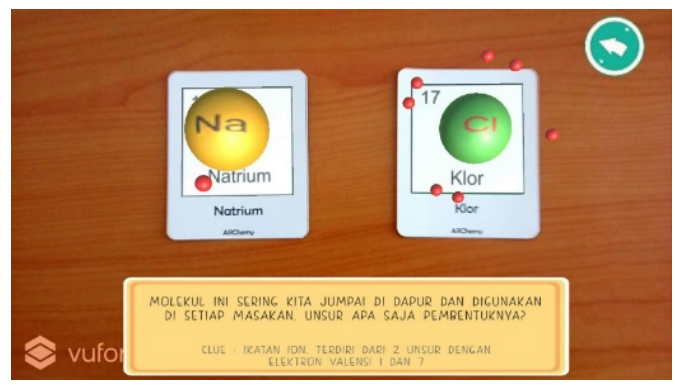

Fig. 3. ARChemy Game

This ARChemy app is Android based. The Android specifications required for the ARChemy app are the minimal Android 4.4 Kitkat operating system, 2 GB RAM, $5 \mathrm{MP}$ or more camera, has $720 \times 1280$ pixels screen resolution, and has a gyroscope sensor. 
After programming is done and the application can be run on the target device, next is usability test to students of class ten. This is done to determine the feasibility level of ARChemy game application. The usability testing aspect tested to the students was adapted from the usability questionnaire from USE Questionnaire [25]. The questionnaire included usefulness, ease of use, ease of learning, and satisfaction indicators.

The test result of usefulness indicator is $85.29 \%$, ease of use is $86.27 \%$, ease of learning is $80.88 \%$, and satisfaction is $87.13 \%$. While the percentage of usability feasibility of 34 students of class $\mathrm{X}$ obtained a percentage of $85.07 \%$ and stated "very good". So the application is declared good in terms of usability.

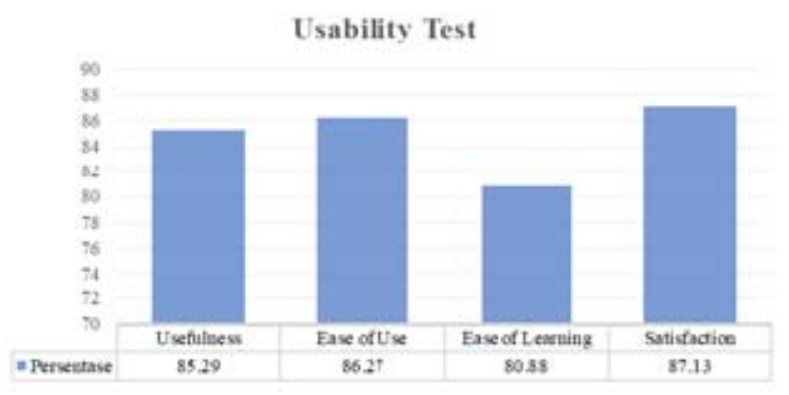

Fig. 4. Graph of Usability Test

Augmented Reality technology can be applied in various fields, not only Vocational Education. Vocational education will really feel the impact of augmented reality over the next year or so. Augmented Reality can have a positive impact in vocational education, such as:

- Provides experience in the workplace. Experiencing workplaces can provide the opportunity to experience the reality of being in an unfamiliar working environment.

- Vocational education is all about the learning through practice, the balance between gaining knowledge and building experience. Augmented reality is particularly powerful in this context.

- Reduces the cost of carrying out some learning experience where expensive learning material is necessary.

- Training a student to work specially, because there are also risky activities for the student or another person, and to reduce this risk we can use AR tools. An example is the surgery simulation, i.e. Performing surgeries without putting in danger to the patient's life.

- This could be the way to explain complex object, visualization of element related to technical training.

Vocational education activities require the purchase of expensive material that can be changed by practices using virtual parts and devices. Vocational educators may plan effective strategies, adapted to constructivist and connective theories to improve the learning, according to their new learning way and also could reduce the cost.

\section{CONCLUSION}

In the current era of disruption all are demanded fast and efficient. Many jobs will be replaced with machines, so that jobs will be lost and replaced with new jobs. Disruption occurs in various industry sectors, one of which in education. Technology in education also changes and replaces old ways to teach and learn something. The old way used in learning the shape of the machine, for example, the teacher will have to give an example of the form of the machine so that students can see the parts of the machine. However, by utilizing $\mathrm{AR}$, it can be done quickly, efficiently and does not take up space and cost, and can be used as a medium of learning in schools, laboratories, at home anywhere and anytime.

\section{ACKNOWLEDGMENT}

The research team would like to thank Prof. Dr. Fathur Rokhman, M.Hum., Rector of State University of Semarang (Unnes), Dr. Nur Qudus M.T, Dean of the Faculty of Engineering, Dr.-Ing. Dhidik Prastiyanto, S.T., M.T., Chairman of the Department of Electrical Engineering, and Staff Employees Faculty of Engineering Unnes.

\section{REFERENCES}

[1] Kasali, Rhenald. (2017). Disruption. Jakarta: PT Gramedia.

[2] Bacca, J., Baldiris, S., Fabregat, R., \& Graf, S. (2014). Augmented Reality Trends in Education: A Systematic Review of Research and Applications. Educational Technology \& Society, 17(4), 133-149.

[3] Roslidah, N. \& Ferary, D. (2018). Integrasi TIK dalam Pendidikan Vokasi Inggris. Sistem Pendidikan Vokasi di Inggris. London: Kantor Atase Pendidikan dan kebudayaan, Kedutaan Besar Indonesia (KBRI) London.

[4] Fehling, C. D., Mueller, A., \& Aehnelt, M. (2016). Enhancing vocational training with augmented reality. Proceedings of the 16th International Conference on Knowledge Technologies and Datadriven Business. ACM Press.

[5] Azuma, R., Baillot, Y., Behringer, R., Feiner, S., Julier, S., \& MacIntyre, B. (2001). Recent advances in augmented reality. IEEE computer graphics and applications, 21(6), 34-47.

[6] Milgram, P., Takemura, H., Utsumi, A., \& Kishino, F. (1995, December). Augmented reality: A class of displays on the realityvirtuality continuum. In Telemanipulator and telepresence technologies (Vol. 2351, pp. 282-293). International Society for Optics and Photonics.

[7] Klopfer, E., \& Squire, K. (2008). Environmental Detectives - the development of an augmented reality platform for environmental simulations. Educational Technology Research and Development, 56(2), 203-228.

[8] Johnson, L., Becker, S. A., Estrada, V., \& Freeman, A. (2015). NMC horizon report: 2015 library edition (pp. 1-54). The New Media Consortium.

[9] Martin, S., Diaz, G., Sancristobal, E., Gil, R., Castro, M., \& Peire, J. (2011). New technology trends in education: Seven years of forecasts and convergence. Computers \& Education, 57(3), 1893-1906.

[10] Nincarean, D., Ali, M. B., Halim, N. D. A., \& Rahman, M. H. A. (2013). Mobile Augmented Reality: the potential for education. Procedia-Social and Behavioral Sciences, 103, 657-664.

[11] Kesim, M., \& Ozarslan, Y. (2012). Augmented reality in education: current technologies and the potential for education. Procedia-Social and Behavioral Sciences, 47, 297-302.

[12] Di Serio, A., Ibáñez, M. B., \& Kloos, C. D., (2012). Impact of an augmented reality system on students' motivation for a visual art course. Computers \& Education Journal, 1-11.

[13] Dror, I. E. (2008). Technology enhanced learning: The good, the bad, and the ugly. Pragmatics \& Cognition, 16(2), 215-223.

[14] Barreira, J., Bessa, M., Pereira, L. C., Adão, T., Peres, E., \& Magalhães, L. (2012). MOW: Augmented Reality game to learn words in different languages: Case study: Learning English names of 
animals in elementary school. In Information Systems and Technologies (CISTI), 2012 7th Iberian Conference on (pp. 1-6). IEEE.

[15] Vallino, J. R., \& Brown, C. M. (1998). Interactive augmented reality (Doctoral dissertation, University of Rochester. Dept. of Computer Science).

[16] Chen, P., Liu, X., Cheng, W., \& Huang, R. (2017). A review of using Augmented Reality in Education from 2011 to 2016. In Innovations in Smart Learning (pp. 13-18). Springer, Singapore.

[17] Saidin, N. F., Halim, N. D. A., \& Yahaya, N. (2016). Designing Mobile Augmented Reality (MAR) for Learning Chemical Bonds. In Proceedings of the 2nd International Colloquium of Art and Design Education Research (i-CADER 2015) (pp. 367-377). Springer, Singapore.

[18] Tasker, R., \& Dalton, R. (2006). Research into practice: visualisation of the molecular world using animations. Chemistry Education Research and Practice, 7(2), 141-159.

[19] Christyowidiasmoro, C., \& Sumpeno, S. (2015). Chemical Bonds Visualization using Particle Effect and Augmented Reality. IPTEK Journal of Proceedings Series, (1).

[20] Seo, D., Kim, M., \& Kim. J., (2017). Multi-Device Based AR (Augmented reality) Visualization \& Interaction of Modeling \&
Simulation Analysis Results. International Journal of Control and Automation Vol. 10, No. 5, page 209-220.

[21] Boletsis, C., \& McCallum, S. (2013). The table mystery: An augmented reality collaborative game for chemistry education. In International Conference on Serious Games Development and Applications (pp. 86-95). Springer, Berlin, Heidelberg.

[22] Buchart, B. (2011). Augmented reality for smartphones: A guide for developers and content publishers. Techwatch Report JISC Observatory.

[23] Billinghurst, M., \& El-Sana, J. (2010). In-place sketching for content authoring in augmented reality games. In Virtual Reality Conference (VR), 2010 IEEE (pp. 91-94). IEEE.

[24] Stapleton, C. B., Hughes, C. E., \& Moshell, J. M. (2002). Mixed reality and the interactive imagination. In Proceedings of the First Swedish-American Workshop on Modeling and Simulation (pp. 3031).

[25] Lund, A. M. (2001). Measuring usability with the use questionnaire12. Usability interface, 8(2), 3-6.G. Eason, B. Noble, and I.N. Sneddon, "On certain integrals of Lipschitz-Hankel type involving products of Bessel functions," Phil. Trans. Roy. Soc. London, vol. A247, pp. 529-551, April 1955. (references) 